Gut, 1980, 21, 602-606

\title{
Prevention of aspirin-induced faecal blood loss by prostaglandin $\mathrm{E}_{2}^{*}$
}

\author{
M M COHEN, GLADYS CHEUNG, AND D M LYSTER.
}

From the Departments of Surgery and Pathology, University of British Columbia, Vancouver, BC, Canada

SUMMARY Prostaglandins have been shown in animal laboratory studies to be capable of protecting the gastrointestinal tract against injury by exogenous agents. This study was conducted to determine if prostaglandin $\mathrm{E}_{2}\left(\mathrm{PGE}_{2}\right)$, which is native to the human gastric mucosa, could influence the increase in faecal blood loss associated with the ingestion of aspirin (ASA). A randomised doubleblind study was performed on 27 healthy men. Faecal blood loss was measured by the ${ }^{51} \mathrm{Cr}$ labelled red cell technique. ASA (600 mg four times daily) caused a significant increase in faecal blood loss. $\mathrm{PGE}_{2}$ ( $1 \mathrm{mg}$ four times daily) had no effect on faecal blood loss when administered alone. When given in addition to ASA it resulted in a faecal blood loss not significantly different from control. No significant alteration in intestinal transit occurred. It is concluded that $\mathrm{PGE}_{2}$ protects man from the gastrointestinal injury associated with ASA.

Prostaglandin $\mathrm{E}_{2}\left(\mathrm{PGE}_{2}\right)$ occurs naturally in human gastric mucosa, ${ }^{1}$ but its physiological role is not clear. Inhibition of acid secretion ${ }^{2}$ and stimulation of mucus production ${ }^{34}$ and nonparietal cell secretion $^{5-7}$ have been documented. In animal experiments a 'cytoprotective' property has been described $^{8}$ by which gastric erosions induced by a variety of exogenous agents can be prevented by prostaglandin analogues incapable of acid inhibition or by doses of $\mathrm{PGE}_{2}$ below the threshhold for acid inhibition. ${ }^{9}$ There is evidence in man that aspirininduced changes in gastric transmucosal potential difference can be prevented by $\mathrm{PGE}_{2}{ }^{10}$

In clinical practice, aspirin may cause significant gastrointestinal bleeding ${ }^{11}$ probably due to injury to the gastric mucosa. ${ }^{12}$ Most individuals on large doses of aspirin lose an extra few millilitres of blood each day in their faeces. ${ }^{13} 14$

This study was conducted to determine if oral $\mathrm{PGE}_{2}$ could prevent this increased faecal blood loss associated with the ingestion of aspirin.

\section{Methods}

Thirty-one healthy adult males (aged 19-40 years) were admitted to the trial. All gave informed written

- This work was reported at the Fourth International Prostaglandin Conference, Washington, DC, May 1979.

†Address for correspondence: Dr M M Cohen, Department of Surgery, Mount Sinai Hospital, 600 University Avenue, Toronto, Ont., M5G 1x5 Canada.

Received for publication 7 January 1980 consent and the study was approved by the ethics committee of the University of British Columbia. Initial screening comprised a full medical history, physical examination, and standard laboratory studies. Subjects were excluded who were known to be taking steroids within the past six months, or aspirin or any other analgesics within the previous two weeks. Individuals with a history of ulcer disease or haemorrhoids were also excluded.

The subjects were randomly allocated to one of four groups using a table of random numbers (Table 1). All drugs were administered before meals and at bedtime. PGE 2 was started 24 hours before the ASA and individual doses were taken 30 minutes before ASA. PGE 2 was supplied as $1.0 \mathrm{mg}$ in $5 \mathrm{ml}$ $10 \%$ ethanol, which was diluted by the subject in $100 \mathrm{ml}$ tap water. ASA was supplied as nonbufferred $300 \mathrm{mg}$ tablets. Drug administration

Table 1 Treatment programme, transit time (days) and day 7 serum salicylate $(\mathrm{mg} / \mathrm{dl})$ in the four groups of volunteers

\begin{tabular}{|c|c|c|c|c|c|c|c|}
\hline \multirow[b]{2}{*}{ Group } & \multirow[b]{2}{*}{ No. } & \multicolumn{4}{|c|}{ Day of study } & \multirow{2}{*}{$\begin{array}{l}\text { Mean } \\
\text { Transit time } \\
( \pm S D)\end{array}$} & \multirow{2}{*}{$\begin{array}{l}\text { Mean } \\
\text { salicylate } \\
\text { level } \\
( \pm S D)\end{array}$} \\
\hline & & 4 & 5 & 6 & 7 & & \\
\hline $\begin{array}{l}\text { I } \\
\text { II } \\
\text { III } \\
\text { IV }\end{array}$ & $\begin{array}{l}6 \\
9 \\
7 \\
5\end{array}$ & $\begin{array}{l}P_{1} \\
P_{1} \\
P_{G} \\
\text { PG }\end{array}$ & $\begin{array}{l}P_{1} P_{2} \\
P_{1} A \\
\text { PGA } \\
\text { PGP }_{2}\end{array}$ & $\begin{array}{l}P_{1} P_{2} \\
P_{1} A \\
\text { PGA } \\
\text { PGP }_{2}\end{array}$ & $\begin{array}{l}P_{1} P_{2} \\
P_{1} A \\
\text { PGA } \\
\text { PGP }\end{array}$ & $\begin{array}{l}3 \cdot 2 \pm 1 \cdot 2 \\
3 \cdot 0 \pm 0.7 \\
3 \cdot 3 \pm 1 \cdot 0 \\
3 \cdot 4 \pm 0.9\end{array}$ & $\begin{aligned} 2 \cdot 5 & \pm 1 \cdot 3 \\
10 \cdot 0 & \pm 2 \cdot 8 \\
10 \cdot 8 & \pm 3 \cdot 1 \\
3 \cdot 2 & \pm 0.56\end{aligned}$ \\
\hline
\end{tabular}

$P_{1}$ : prostaglandin placebo. $A$ : aspirin $600 \mathrm{mg} \times 4$ daily. $P_{2}:$ aspirin placebo. $P G: P_{2} 1 \mathrm{mg} \times 4$ daily. 
started on the morning of the fourth day of stool collection. The placebo tablets were plain white scored tablets of lactose.

\section{INTESTINAL TRANSIT}

Intestinal transit was measured during the period of drug administration using a modification of the technique described by Hinton et al..$^{15}$ Twenty radioopaque plastic pellets $(22 \mathrm{mg})$ were swallowed with the first dose of $\mathrm{PGE}_{2}$ or placebo. Another 20 pellets were taken with the first dose of ASA or placebo. Each 24 hour stool collection was radiographed before being homogenised until all the pellets could be accounted for. Intestinal transit was determined in days as the time taken for 36 pellets to pass.

\section{FAECAL BLOOD LOSS}

Faecal blood loss was measured by the ${ }^{51} \mathrm{Cr}$ labelled red blood cell technique. ${ }^{16}$ Approximately $20 \mathrm{ml}$ of blood was withdrawn and $15 \mathrm{ml}$ transferred to a vial containing ACD solution for labelling. The remaining $5 \mathrm{ml}$ was used to measure radioactivity present in the subject's blood ('residual sample'). At least two minutes later exactly $10 \mathrm{ml}$ of tagged blood was reinjected intravenously. Starting at midnight of the following day all stools passed were collected in plastic bags for 10 days, each 24 hour collection being separately labelled. Blood samples were taken on each weekday. Blood radioactivity was counted on $3 \mathrm{ml}$ samples, using a Picker Autowell sample counter. The entire daily collection of stool was homogenised, weighed, and a sample counted in a Tubor sample counter. In order to relate the stool counts to the whole blood counts, which were performed on different instruments, standards were prepared which allowed for the variable geometry. A 'conversion factor' was calculated from the counts of each standard, and this was applied to all stool counts. All stool samples and the appropriate standards were counted on the day they were obtained.
CALCULATIONS

Background was subtracted from all samples and they were decayed to a common day postinjection. Each stool sample was corrected for decay, daily difference in instrument efficiency as determined by the standard preparation and for the difference in the two counting instruments using the 'conversion factor'. Total activity of the entire 24 hour stool collection was calculated. All blood samples were counted and a line of best fit calculated to provide total activity per $\mathrm{ml}$ of blood for each study day. The amount of blood ( $\mathrm{ml}$ ) in each 24 hour stool collection was obtained by dividing the 24 hour stool activity by the activity per $\mathrm{ml}$ of blood obtained from the subject the previous day.

\section{ANALYSIS OF DATA}

A one-way analysis of variance ${ }^{17}$ was computed for each study day. The pooled error variances so derived and Dunnett's $t$ statistic were used to compare all active drug treatment means to the placebo control mean for each study day. A onesided $\alpha=0.05$ level test was used. As the sample size varied among the treatment groups, Dunnett's $t$ statistic was calculated using the harmonic mean of the sample sizes.

Serum salicylate was measured at the time of initial screening and on the last day of ASA administration the blood being drawn just before the second last dose of ASA. The method of assay was by Trinder's method which gives a low background value for serum which contains no salicylate. The initial laboratory studies were repeated at the conclusion of the study.

\section{Results}

Four of the original subjects were not included in the analysis of the data: two lost their drug supply and two had baseline faecal blood content greater than $5 \mathrm{ml} /$ day. The only side-effect recorded

Table 2 Mean faecal blood loss $( \pm S D)$

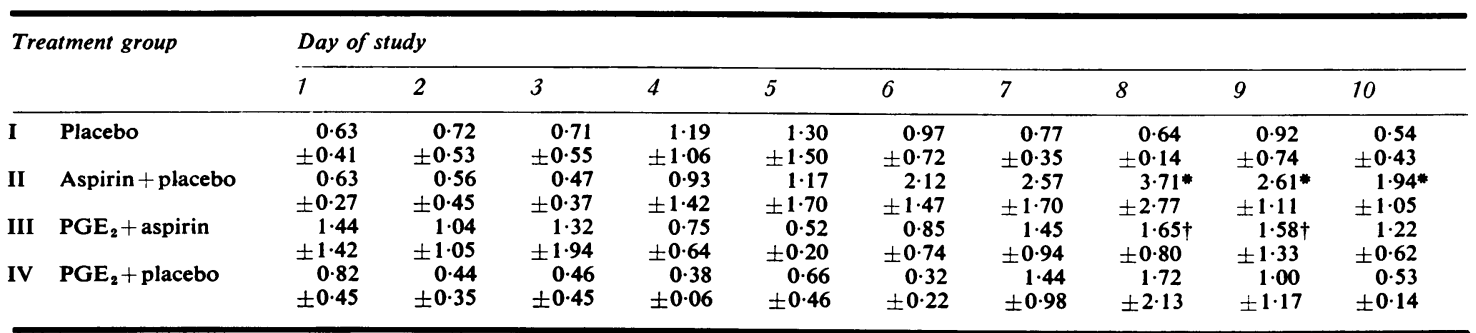

* Significantly different from placebo $(\alpha=0.05$ level one-sided test).

$\dagger$ Significantly different from aspirin plus placebo $(\alpha=0.05$ level one-sided test) 
during the study was transient mild diarrhoea, lasting one day only, in two of the subjects who received $\mathrm{PGE}_{2}$.

There was no difference in intestinal transit between the four groups (Table 1), and the time taken for $90 \%$ of the radiopaque pellets to pass was comparable with that found by Hinton et al. in normal subjects. ${ }^{15}$ The mean serum salicylate increased in the group taking aspirin and placebo and in the group taking aspirin and $\mathrm{PGE}_{2}$ to values which were not significantly different from each other but were significantly higher $(P<0.01)$ than those in the double placebo group or the $\mathrm{PGE}_{2}$ and placebo group (Table 1).

Faecal blood loss in $\mathrm{ml} /$ day in the four treatment groups is given in Table 2 and shown in the Figure. Subjects treated with aspirin and placebo showed a significant $(\mathrm{P}<0.05)$ increase in blood loss compared with placebo-treated subjects. The highest blood
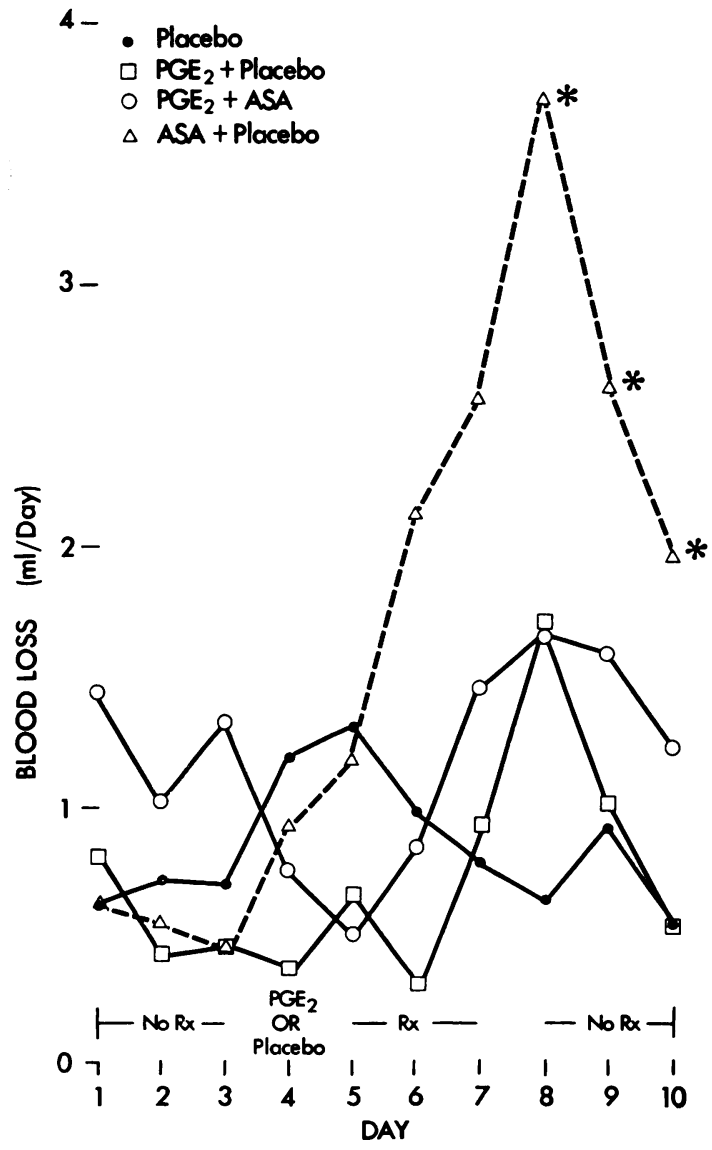

Figure Faecal blood loss during each day of the study in the four treatment groups. Asterisks indicate losses significantly $(\mathrm{P}<0.05)$ greater than control. content in the stool occurred one day after aspirin administration was stopped-that is, it coincided with the second day of aspirin treatment after intestinal transit time was allowed for. Mean blood loss in the groups who received aspirin plus $\mathrm{PGE}_{2}$ or $\mathrm{PGE}_{2}$ plus placebo was not significantly different from that in the double placebo group. Mean blood loss in the group receiving aspirin plus $\mathrm{PGE}_{2}$ was significantly less $(\mathrm{P}<0.05)$ than in the group receiving aspirin plus placebo.

No changes were detected in the laboratory values at the completion of the study.

\section{Discussion}

The results of this study confirmed our preliminary data $^{18}$ and indicate that oral $\mathrm{PGE}_{2}$ will protect the human stomach against the damage normally caused by standard therapeutic doses of aspirin. Preliminary data also show that the damage done by indomethacin in arthritic patients can be similarly prevented. ${ }^{19}$

The concept that prostaglandins, which are synthesised by the gastric mucosa, play a role in protecting the gastric mucosa against injury is attractive. A 'cytoprotective' action of the prostaglandins has been known for some years, but it has only recently been recognised that this action is unrelated to inhibition of acid secretion. Thus the precise mechanism of this protective action remains unclear. Prostaglandins have several additional actions on the gastric mucosa all of which are potentially beneficial. Mucus secretion is stimulated, ${ }^{34}$ bicarbonate secretion is stimulated, ${ }^{5-719}$ and blood flow is increased. ${ }^{21-23} \mathrm{Al}-$ though the prostaglandins have no effect on the normal gastric mucosal barrier, ${ }^{24}{ }^{25}$ there is evidence that prostaglandin can prevent ${ }^{10}$ and reverse ${ }^{26}$ damage to the gastric mucosal barrier. The results of this investigation do not permit deductions about the mechanism of action of prostaglandins but clearly confirm that the protection afforded is unrelated to acid inhibition as oral $\mathrm{PGE}_{2}$ has no effect on human gastric acid secretion. ${ }^{27}$

Aspirin, indomethacin, and the other more recently introduced non-steroid anti-inflammatory analgesics all inhibit prostaglandin synthesis and all cause damage to the gastric mucosa. The proof that these agents damage the mucosa as the direct result of the inhibition of prostaglandin synthetase is still lacking. The indirect evidence is accumulating and our results add human data to that obtained from animal studies.

Aspirin is the most widely used of all drugs and in the United States alone it is estimated that 
20 to 30 tons are consumed daily..$^{28}$ The majority of individuals who take therapeutic doses of aspirin lose an extra few millilitres of blood daily in their stool, ${ }^{1314}$ and in a few who are sensitive there can be frank clinical bleeding. ${ }^{1129}$ Ingelfinger ${ }^{20}$ has wryly calculated that the more than 20 thousand million tablets of aspirin consumed in the United States annually cause 10 million litres of blood to go down the toilet per year.

This trial suggests a potential clinical application of the prostaglandins in the prevention of this blood loss and possibly also the gastric upsets associated with the use of aspirin. The dose of $\mathrm{PGE}_{2}$ used in this study (4 mg/day) caused mild transient diarrhoea in two subjects and is certainly too large to be administered to women who might be pregnant. If a lower dose of $\mathrm{PGE}_{2}$ could be shown to be equally effective in preventing mucosal damage this would open up the possibility of a combination of aspirin and $\mathrm{PGE}_{2}$ as perhaps the ideal analgesic. It remains to be shown, however, that this combined therapy is as effective as an anti-inflammatory analgesic.

We are grateful to the Upjohn Co., Kalamazoo, Michigan, USA for providing the drugs used in this trial and for financial support. This work was also supported by the Canadian MRC Grant No. MA5316. We are indebted to Gayle Henderson for typing the manuscript.

\section{References}

${ }^{1}$ Bennett A, Murray JG, Wyllie JH. Occurrence of prostaglandin $E_{2}$ in human stomach and a study of its effect on human isolated gastric muscle. Br J Pharmacol 1968; 32: 339-49.

${ }^{2}$ Newman A, Prado J, Philippakos D, Misiewicz JJ. The intravenous effect of infusions of prostaglandin $\mathrm{E}_{2}$ and $\mathrm{F}_{2 \alpha}$ on human gastric function. Gut 1975; 16: 272-6.

${ }^{3}$ Bolton JP, Palmer D, Cohen MM. Effect of the $E_{2}$ prostaglandins on gastric mucus production in rats. Surg Forum 1976; 27: 402-3.

${ }^{4}$ Tao P, Scruggs W, Wilson DE. The effects of a prostaglandin endoperoxide analogue on canine gastric acid and mucus secretion. Dig Dis Sci 1979; 24: 449-54.

${ }^{5}$ Bolton, JP, Palmer D, Cohen MM. Stimulation of mucus and non-parietal secretion by the $\mathrm{E}_{2}$ prostaglandins. Am J Dig Dis 1978; 23: 359-64.

${ }^{6}$ Bolton JP: Cohen MM. Stimulation of non-parietal cell secretion in canine Heidenhain pouches by $16,16-$ dimethyl prostaglandin $\mathrm{E}_{2}$. Digestion 1978; 17: 291-9.

${ }^{7}$ Garner A, Heylings JR. Stimulation of alkaline secretion in amphibian-isolated gastric mucosa by $16,16-$ dimethyl $\mathrm{PGE}_{2}$ and $\mathrm{PGF}_{2 x}$. Gastroenterology 1979; 76: 497-503.

${ }^{8}$ Robert A, Schultz JR, Nezamis JE, Lancaster C.
Gastric antisecretory and antiulcer properties of $\mathrm{PGE}_{2}$, 15-methyl $\mathrm{PGE}_{2}$, and 16,16-dimethyl $\mathrm{PGE}_{2}$. Intravenous, oral and intrajejunal administration. Gastroenterology 1976; 70: 359-70.

${ }^{9}$ Robert A. Antisecretory, antiulcer, cytoprotective and diarhoeogenic properties of prostaglandins. $A d v$ Prostaglandin Thromboxane Res 1976; 2: 507-20.

${ }^{10}$ Cohen MM, Pollett JM. Prostaglandin $E_{2}$ prevents aspirin and indomethacin damage to human gastric mucosa. Surg Forum 1976; 27: 400-1.

${ }^{11}$ Jick H, Porter J. Drug-induced gastrointestinal bleeding. Lancet 1978; 2: 87-9.

${ }^{12}$ Loebl DH, Craig RM, Culic DD, Ridolfo AS, Falk J, Schmid FR. Gastrointestinal blood loss: effect of aspirin, fenoprofen, and acetaminophen in rheumatoid arthritis as determined by sequential gastroscopy and radio-active fecal markers. JAMA 1977; 237: 976-81.

${ }^{13}$ Grossman MI, Matsumoto KK, Lichter RJ. Fecal blood loss produced by oral and intravenous administration of various salicylates. Gastroenterology 1961; 40: 383-8.

${ }^{14}$ Croft DN, Wood PHN. Gastric mucosa and susceptibility to occult gastrointestinal bleeding caused by aspirin. $\mathrm{Br}$ Med $J$ 1967; 1 : 137-41.

${ }^{15}$ Hinton JM, Lennard-Jones JE, Young AC. A new method for studying gut transit times using radioopaque markers. Gut 1969; 10: 842-7.

${ }^{16} \mathrm{Holt}$ PR. Measurement of gastrointestinal blood loss in subjects taking aspirin. $J$ Lab Clin Med 1960; 56: 717-26.

${ }^{17}$ Winer BJ. Statistical principles in experimental design. New York: McGraw-Hill 1962: 46-102.

${ }^{18}$ Cohen MM. Mucosal cytoprotection by prostaglandin $\mathrm{E}_{2}$. (Letter.) Lancet 1978; 2: 1253-4.

${ }^{19}$ Johansson C, Kollberg B, Nordemar R, Bergström S. Mucosal cytoprotection by prostaglandin $\mathrm{E}_{2}$. (Letter.) Lancet 1979; 1: 317.

${ }^{20}$ Kauffman GL Jr, Grossman MI. Gastric alkaline secretion: Effect of topical and intravenous 16-16 dimethyl prostaglandin $\mathrm{E}_{2}$ (Abstract). Gastroenterology 1979; 76: 1165 .

${ }^{21}$ Main IHM, Whittle BJR. The effects of E and A prostaglandins on gastric mucosal blood flow and acid secretion in the rat. Br J Pharmacol 1973; 49: 428-36.

${ }^{22}$ Gerkens JF, Flexner C, Oates JA, Shand DG. Prostaglandin and histamine involvement in the gastric vasodilator action of pentagastrin. J Pharmacol Exp Ther 1977; 201 : 421-426.

${ }^{23}$ Boughton-Smith NK, Vane JR, Whittle BJR. Effects of prostacyclin $\left(\mathrm{PGI}_{2}\right), \mathrm{PGI}_{1}$, and 6-oxo-PGF ${ }_{1 \alpha}$ on the rat gastric mucosa. Br J Pharmacol 1978; 62: 413P.

${ }^{24}$ Bolton JP, Cohen MM. The effect of 16,16-dimethyl prostaglandin $\mathrm{E}_{2}$ on the gastric mucosal barrier. Gut 1979; 20: 513-7.

${ }^{25}$ Bolton JP, Cohen MM. Permeability effects of the $E_{2}$ prostaglandins on canine gastric mucosa. Can J Physiol Pharmacol 1979; 57: 1082-7.

${ }^{26}$ Bolton JP, Cohen MM. The effect of prostaglandin $E_{2}$, 15-methyl prostaglandin $\mathrm{E}_{2}$ and metiamide on established canine gastric mucosal barrier damage. Surgery 1979; 85: $333-338$

${ }^{27}$ Karim SMM, Carter DC, Bhana D, Ganesan PA. 
Effect of orally administered prostaglandin $E_{2}$ and its 15-methyl analogues on gastric secretion. $\mathrm{Br}$ Med $J$ 1973; 1 : 143-6.

${ }^{28}$ Abrishami MA, Thomas J. Aspirin intolerance-a review. Ann Allergy 1977; 39: 28-37.
${ }^{29}$ Levy M. Aspirin use in patients with major upper gastrointestinal bleeding and peptic-ulcer disease. N Engl J Med 1974; 290: 1158-62.

${ }^{30}$ Ingelfinger FJ. The side effects of aspirin (Editorial). $N$ Engl J Med 1974; 290: 1196-7. 